\title{
Biomarker science: on a theme of personalized medicine
}

\author{
Richard C. Becker $\cdot$ Susan Smyth
}

Published online: 20 April 2012

(C) Springer Science+Business Media, LLC 2012

Imagine a scenario where drug development and its rational application to patient care begins with a platform of biomarkers derived from phenotypic screening [1]—an approach associated with $50 \%$ more FDA-approved firstin-class drugs than target-based drug screening [2]. Now envision an academic community-industry collaborative

Fig. 1 Drug discovery and development is an iterative process that includes systemsbased biology, pathophenomics, systems-based pharmacology and biomarker science employed as a continuum of biomedicine across multiple points of interface

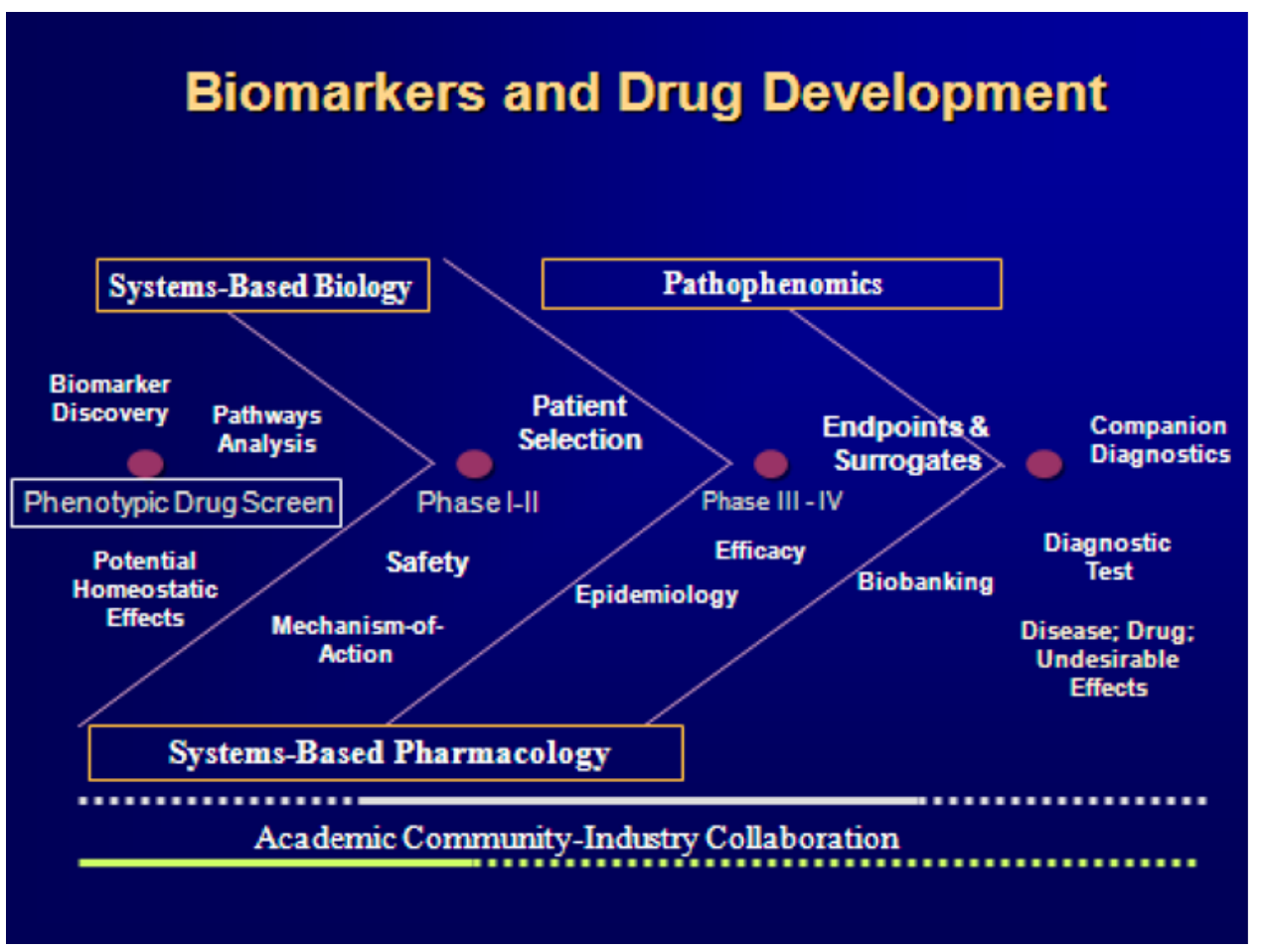

R. C. Becker $(\square)$

Divisions of Cardiology and Hematology, Duke University School of Medicine, Pratt Street, Durham, NC 27705, USA

e-mail: richard.becker@duke.edu

\section{S. Smyth}

The Gill Heart Institute, Lexington VA Medical Center,

Lexington, KY, USA

e-mail: ssmyt2@email.uky.edu 
relationship where-in systems-based biology, driven by the rapidly evolving technologies of genetics, genomics, transcriptomics, proteomics and metabolomics is integrated, employing complex informatic algorithms and biological networks (interactome) with systems pharmacology, an in-depth understanding of the molecular basis of disease and large-scale clinical data sets (pathophenomics) [3]. The end-result? A comprehensive, flexible and translatable systems-based model for rational drug development formulated to restore human biological homeostasis and preemptively identify undesirable adverse effects. The model also provides a direct pathway and iterative means to develop diagnostic tools that both reflect and capture drug properties, the phenotypic expression of disease and non-homeostatic maintaining drug and disease responses (Fig. 1).

This special issue of the journal highlights biomarker science and its pivotal role in changing the dated landscape of a reductionist mentality of one drug, one target and one disease as being applicable to a highly complex universe. The special issue also heralds a new section of the journal that is dedicated to Biomarker Science.

Fellows Forum section, a recurring element of the journal that recognizes scholarly activities in trainees participating in the continuum of cardiovascular science, follows the Biomarker theme of the issue with two original articles on biomarkers in thrombotic disorders. The first paper by Kim et al. [4] shows that activated thrombinactivatable fibrinolysis inhibitor accumulates in baboons during E. coli sepsis, positioning it to influence fibrinolysis and inflammation. In the second paper, Rios et al. [5] examine the association between end-stage kidney disease requiring dialysis, vascular-access thrombosis, and plasma levels of von Willebrand factor and its cleaving enzyme, ADAMTS13. Both articles fulfill the intent of the Forum, which is to provide trainees with an avenue for publication of meritorious original work devoted to fundamental science in the areas of cardiovascular disease, preclinical and clinical research, global health, and epidemiology.

\section{References}

1. Loscalzo J (2012) Personalized cardiovascular medicine and drug development: time for a new paradigm. Circulation 125(4): 638-645

2. Swinney D, Anthony J (2011) How were new medicines discovered? Nat Rev Drug Discov 10(7):507-519

3. Loscalzo J, Kohane I, Barabasi AL (2007) Human disease classification in the postgenomic era: a complex systems approach to human pathobiology. Mol Syst Biol 3:124

4. Kim PY, Kim PYG, Taylor FB Jr, Nesheim ME (2012) Thrombinactivatable fibrinolysis inhibitor is activated in vivo in a baboon model of Escherichia coli induced sepsis. J Thromb Thrombolysis. doi:10.1007/s11239-011-0676-4

5. Rios DRA, Fernandes AP, Figueiredo RC, Guimarães DAM, Ferreira CN, Simões e Silva AC, Carvalho MG, Gomes KB, Dusse LMSA (2012) Relationship between ABO blood groups and von Willebrand factor, ADAMTS13 and factor VIII in patients undergoing hemodialysis. J Thromb Thrombolysis. doi:10.1007/ s11239-012-0719-5 